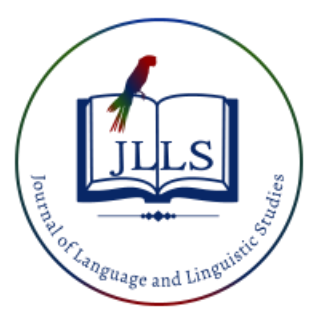

Available online at www.jlls.org

JOURNAL OF LANGUAGE

AND LINGUISTIC STUDIES

ISSN: $1305-578 \mathrm{X}$

Journal of Language and Linguistic Studies, 17(1), 360-376; 2021

\title{
Basque informal talk increasingly restricted to men: The role of gender in the form of address hika
}

\author{
Garbiñe Bereziartua $^{\text {a } 1}$ (iD, Beñat Muguruza ${ }^{\text {b }}$ iD \\ ${ }^{a}$ University of the Basque Country (UPV/EHU), Donostia-San Sebastian, Spain \\ ${ }^{b}$ University of the Basque Country (UPV/EHU), Portugalete, Spain
}

APA Citation:

Bereziartua, G., \& Muguruza, B. (2021). Basque informal talk increasingly restricted to men: The role of gender in the form of address hika. Journal of Language and Linguistic Studies, 17(1), 360-376. Doi: 10.52462/jlls.22

Submission Date: 06/01/2021

Acceptance Date: 14/03/2021

\begin{abstract}
Many languages make a T/V distinction when addressing an interlocutor, and Basque also has two main levels of formality: zuka (formal) and hika (informal). The peculiarity of the Basque informal form of address hika is that its verbal morphology varies depending on the addressee's gender. The use of hika has dramatically decreased in most parts of the Basque Country, and even in those areas where it is still widely spoken, the female form (noka) is on the verge of extinction. In this study, we seek to provide data to confirm this decreasing trend to examine the reasons behind such pronounced gender differences in usage. We used a questionnaire consisting of both numeric and narrative parts to elicit data, and 1,247 participants responded. The results corroborate the decreasing tendency found in other studies, and the loss of female forms is attributed to several factors including lack of prestige, transmission gap, and sexism.
\end{abstract}

Keywords: a form of address; T/V distinction; gender; language prestige; Basque

\section{Introduction}

For decades, the issue of gender differences in the use of language has fascinated social researchers in the fields of linguistics, sociolinguistics, and communication. The relationship between gender and language has been a thoroughly analyzed research topic. In this article, we seek to contribute to this tradition by considering the prevalence of male linguistic forms within the Basque language. This language-Euskara — is a minoritized language within the Basque Country, as Spanish is the majority language in the southern part of the country and French is the majority language in the north (Urla, 2012). In this article, however, we focus on a specific feature of the Basque language and the sociolinguistic performances that this feature brings into being.

\footnotetext{
${ }^{1}$ Corresponding author.

E-mail address: garbine.bereziartua@ehu.eus
} 


\subsection{Literature review}

\subsubsection{Hika, the Basque informal form of address}

Like many languages, Basque has different forms of address depending on the level of formality that is appropriate for each context. Historically, there are four forms (cf. Alberdi, 2018) but only two are used to a significant extent in the 21st century: $z u k a$ (formal) and hika (informal). There are similar forms, for instance, in Spanish and French with the formal forms usted and vous and the informal forms $t u$ and $t u$, respectively. A similar phenomenon occurs in Basque with $z u$ as the formal form and $h i$ as the informal form. However, in Basque, the informal hika form is much more marked than the Spanish informal form (tú) and the French informal form (tu). As Echeverria (2003, p. 397) explains, zuka "is the pragmatically unmarked form of address," whereas hika is to be used only if the speaker, the addressee, and the context meet certain specific criteria that we will explain below.

Another distinction between Basque and the other prevalent languages in the Basque Country is in terms of gender distinctions. Basque has no grammatical gender as Spanish and French do. Nouns may have a natural gender (e.g., 'behorra,' mare; 'semea,' son), but the distinction is very seldom grammatically represented. However, one of the few elements where gender division is explicit in Basque involves the informal form of address, hika. To put it simply, when Basque speakers use the so-called familiar register, most verbal forms vary depending on the addressee's gender, as illustrated in Table 1. Example (a) in the table shows the formal zuka and there is no gender distinction. The rest of the sentences are in hika. It is called noka when the addressee is a female and the form is represented either with the morpheme ' $n$ ' (example b) at the end or '-na-' within the inflected verb (example c). When we have a male addressee we use toka, and the verb takes a '-k' (example d) or an 'a-' (example e). Some verbal forms are gender invariable in hika (example f). There are only a handful of gender invariable forms in the language, but some are very recurrent. Here we will leave out the issue of allocutivity (see Oyharçabal, 1993), which is essential to fully understand how hika works but does not contribute significantly to the sociolinguistic perspective of our research.

Table 1. The forms of address zuka and hika in their different forms

\begin{tabular}{lll}
\hline \multicolumn{2}{c}{ Basque } & English \\
\hline a) & Ikusi dut & I have seen it (zuka) \\
b) & Ikusi dun & You have seen it (noka) \\
c) & Ikusi dinat & I have seen it (noka) \\
d) & Ikusi duk & You have seen it (toka) \\
e) & Ikusi diat & I have seen it (toka) \\
f) & Ikusi haut & I have seen you (hika, neutral) \\
\hline
\end{tabular}

According to de Rijk (1991), it has been suggested that "the difference between $h i$ and $z u$ closely corresponds to that between Spanish tú and usted, or that between French $t u$ and vous," but this idea can be misleading because there is not a direct correspondence and "is likely to prove itself a source of trouble to its bearer" (de Rijk, 1991, p. 376). Thus, as a basic premise, the social rules for using hika are different from Spanish and French. Hika has been traditionally used in two types of communicative contexts. In top-down relationships (parents to children, elder to younger, etc.), only the authority is allowed to speak hika (de Rijk, 1991). However, the situation is more complex in peer, solidarity relationships, in which the most common context seems to be when the interlocutor is a sibling or a 
friend (Alberdi, 2018). Within these situations, de Rijk (1991) has argued that the hika form is relevant for the encodement of an attitude of solidarity, and we turn now to those contexts.

Within the peer relationship, the topic and context of conversation seem to influence the use of hika. Some use hika when joking and zuka to talk about more serious matters. As Alberdi (1993) puts it, speakers would use hika in a festive atmosphere, but not in the context of grief.

Age is another important factor. In principle, hika can only be used to address either younger people or people of similar age. De Rijk (1991) argues that hika is not supposed to be used when the addressee is fifteen years older (or more), and although this distance is not clear-cut, Alberdi (1993) suggests that the restriction is often marked by a gap of one generation.

One of the most crucial features to promote or preclude the use of hika is $\operatorname{sex}^{2}$. Alberdi (2018) explains that different-sex relationships are more likely to provoke asymmetric hika treatment, and in general, sex difference is a major hindrance to the use of hika. Likewise, if an asymmetry takes place in the form of address, women will use hika whereas men will use the formal form of address. In a same-sex conversation, men tend to use hika among themselves more often than women.

The degree of familiarity plays an important role, too. Specifically, the closer the relative, the more common it will be to speak in hika (Alberdi, 1993). For instance, in places where the informal form of address is still widely used, siblings typically address each other in hika. Nonetheless, an asymmetry is quite common in this case: women use hika with their brothers more often than vice versa (Alberdi, 1993).

It has been observed that sharing a common ground or a certain affinity between the speakers may be an important trigger for the use of hika. In de Rijk's (1991, pp. 376-377) words, "the kind of solidarity that is relevant consists, above all, in being subject to similar living conditions: children raised in the same family, hamlet or neighborhood, workers on the same farm or in the same factory, and so on." Indeed, hika is considered within the Basque language as "the key marker of solidarity," because it is commonly used with close people (Echeverria, 2003, p. 400). Urla (1995), in her research about Basque free radios, found that radical Basque young people, particularly males, used hika to build "the communicative sphere as an imagined community of 'horizontal comradeship' that is in keeping with free radio's vision of radical democracy" (Urla, 1995, p. 255).

As we previously explained, people use hika in top-down relationships, too. It marks authority and therefore inequality of power in such contexts. In environments such as the family or the workplace, the form of address may be asymmetrical: hika top-down and zuka bottom-up. For instance, in places where hika is still strong, parents usually speak hika to their children (once they grow a little) while children use zuka (Alberdi, 1993; de Rijk, 1991). Other factors such as sharing the same dialect or psychological solidarity are also mentioned by Alberdi (1993). He considers psychological solidarity as particularly important in that liking the interlocutor may have an impact on the use of the form of address, and affection can promote the use of hika.

Among all of these influences on hika usage, an understanding of the influence of gender is critical. There are considerable gender differences in the use of hika, with the female forms (noka) on the verge of disappearing in the $21^{\text {st }}$ century (Alberdi, 1993). Hika has been in decline in the last decades, and it has practically disappeared in many parts of the Basque Country. In some areas, hika still enjoys good health (especially male-addressed forms, toka), but the majority of the Basque-speaking people do not use hika at all, and many of them do not even know how to use it. Men use it the most often, especially with other men. Among women, the use of hika can now be considered marginal (Echeverria, 2016).

\footnotetext{
${ }^{2}$ Here we stick to the original term used by the author ('sex'), although we would nowadays tend to use the term 'gender' instead.
} 


\subsubsection{Gender-related sociolinguistics in hika}

Basque can be thought to be a non-sexist language, especially because of the lack of grammatical gender. However, Barquín (2008) and Juanena (1991) noted that different aspects need to be taken into account to determine whether a language is sexist or not. These include the lexicon of the language, the mere existence of certain words, the lexical gap of some concepts, and the richness or poverty of a given semantic field. Echeverria's (2016) findings also offer a critical view on the putative lack of sexism in Basque. She analyzed a 19th-century Basque translation of the Old Testament, and she concluded that female forms of hika were mainly used to address 'inanimate interlocutors, metaphorically cast as female, for exclusively negative interactional purposes' (Echeverria, 2016, p. 370). Thus, the gender differences in the use of hika forms should be considered as another aspect in which sexist attitudes are observed.

Echeverria (2003) thoroughly analyzed several textbooks used in Basque schools, and her findings revealed a discriminatory use of hika: male forms (toka) were much more usual than female forms (noka). Further, hika was used between male characters or to address a male audience, but sometimes toka forms were used addressing both men and women. Thus, Echeverria (2003, p. 400) concluded that toka is 'becoming the default, gender-neutral form of address' within the informal register. In line with these findings, Juanena (1991) claimed that whenever institutions have decided to integrate hika forms in their propaganda messages, they have only used male forms; that is, they have not considered women and have employed men-directed forms as if they were neutral. She argues for two ways to avoid such discrimination: either not to use hika, or use both male and female forms.

There are other common trends that express sexist attitudes among those who use hika. These include people - generally men - who use the masculine forms when addressing a mixed group as if there were no women present (Barquín 2008), in the same line as Juanena (1991); and peoplegenerally men, again - who habitually use the informal form to address other men but seldom to address women (Legorburu, 2018). Another tendency appeared a few decades ago where women started to be addressed using male forms not only by men but also by other women. Azkue (2000) observed that this phenomenon was not uncommon among the younger speakers, and Ozaita (2015) more recently reached the same conclusion.

Despite these trends, efforts are being made to revitalize hika, and some groups engaged with feminism have begun to consider it a tool for women's empowerment (Legorburu, 2018). Although this issue has not reached the academic arena, there are reasons to believe that societal interest and awareness are increasing.

Lakoff (1973) claimed that 'women experience linguistic discrimination in two ways: in the way, they are taught to use language, and in the way, general language use treats them' (p. 46). Since this early insight, the topic of language and gender has been approached from a variety of angles. In discussing this work, Piller and Pavlenko (2004) describe approaches including a deficit framework (Lakoff, 1975), a dominance framework (West \& Zimmerman, 1983), and a different framework (Chambers, 1995). Feminist poststructuralist approaches understand language as a form of symbolic capital: 'Language use, in turn, is considered a situated process of participation in multiple and overlapping communities of practice, which may entail the negotiation of ways of being a person in that context' (Piller \& Pavlenko, 2004, p. 492). More recent studies bring to the arena approaches related to social constructionism, postmodernism, and feminist sociolinguistics (Holmes, 2007) or propose postfeminism as a critical tool for gender and language study (Litosseliti, Gill \& Garcia Favaro, 2019).

From a social constructionist approach and looking at the form and the use of languages, Ochs (1992) states that ' $[n]$ on-referential indexing of gender may be accomplished through a vast range of morphological, syntactic, and phonological devices available across the world's languages' (p. 339). 
Echeverria (2003) brought these ideas into the Basque context, saying, 'in Ochs's (1992) terms, what these ideologies show is that $h i$ indexes certain social meanings (spontaneity, directness, naturalness, anger, fun, peasantness), which in turn index masculinity' (p. 404). Echeverria (2003) points out other associations between hika and masculinity, as well. For example, Basque speakers who live in settings such as small villages and farms often use hika, as do rural sportsmen or men involved in traditional activities. Then, ' $h i$ becomes a marker of ethnic authenticity most closely associated with male Basque speakers' (Echeverria, 2003, p. 406). On the other hand, based on Urla's (1995) work, where hika is related to free radio stations and radical rock groups, it can be observed that most protagonists are men and that they mostly employ male forms when addressing the whole audience.

The prestige or status of languages also affects language uses. Many researchers have noted that women tend to use high-prestige language varieties more than men (Labov, 1972; Trudgill, 1995). Gal (1979), in Austria, and MacDonald (1989), in Brittany, concluded that women more easily discarded peasant or lower prestige language compared to men, and women were prone to use a higher status language that was related to urban areas. Ochs (1992) observed a similar tendency: 'In British and American English, women tend to use prestige phonological variants more than men of the same social class and ethnicity (p. 340). Echeverria (2003) places this phenomenon in the context of the Basque Country, arguing that at the beginning of the second half of the 20th century, the girls from rural villages who had to go to the city for employment developed inferiority complexes about speaking Basque (low prestige language), so they chose to speak Spanish (high prestige language) instead.

We have seen that prestige-related issues influence the use of different languages, and the same phenomenon is apparent among different registers or forms of address within the very same language. In the case of Basque, that phenomenon involves the relationship between the forms of address zuka and hika. As Echeverria (2003) explains, 'an opposition between prestige and solidarity, initially represented by the Spanish and Basque languages, recurs in discussions about the standard and vernacular Basque, as well as about the two $2^{\text {nd }}$ person singular pronouns, $z u$ and $h i$ ' (p. 293).

Issues related to the prestige of languages bring about several consequences. One recurrent example is that the use of the language (or register or form of address) of lower prestige decreases. That is exactly what has happened with hika (the informal form of address) and especially the variety of the form to address women.

One of the few measurements of the use of hika was conducted in the town of Azpeitia (Soziolinguistika Klusterra, 2016) and the study gave the following figures: $82 \%$ of the conversations that were observed were in Basque, and out of that $82 \%$, only $18 \%$ of the conversations were in hika. The researchers also observed important differences related to gender. In the conversations in which hika forms were used, $45.1 \%$ of the cases involved the use of male forms, whereas $17.5 \%$ involved the use of female forms. In the remaining conversations, either only the personal pronoun 'hi' was used or gender-invariable hika forms were used (see Table 1).

\subsubsection{Reasons for the decrease of female hika forms}

Several researchers have analyzed the reasons for the decline of the use of female hika and have proposed several explanations. Alberdi (1993), Echeverria (2003), Beitia (2017), and Legorburu (2018) refer to the already mentioned low reputation of hika forms in general and female forms of hika in particular. Hika has different connotations for men and women. In the case of men, hika has been linked to solidarity, brotherhood, familiarity, and confidence. In contrast, when women use hika it is associated with rudeness and lack of respect.

In the same vein, the 'iconic' relationship between $h i$ and masculinity is another factor mentioned by Echeverria (2003). She explains that there is a naturalized relationship between hika and masculinity because hika forms seem appropriate for boys and men, but not for girls and women. 
Echeverria (2003) also notes the different historical employment patterns of rural Basque women and men when they were forced into urban life when a livelihood from agriculture became too difficult. Men mostly went to work in factories together with their co-workers from the same town, which made the use of hika possible. In contrast, women were often hired as maids in higher status households, as waitresses, or as shop-clerks. These are employment settings where speaking hika was not welcome.

Another reason for the usage patterns in hika mentioned by Echeverria (2003), Beitia (2017), and Legorburu (2018) involves the public/private dichotomy. The public sphere has been historically maledominated and female forms of hika could only be heard in private circles, so its lack of visibility may have hindered transmission. Meanwhile, male forms of hika are more present on the street, which made transmission possible. That is, the fact that people got used to hearing hika mostly in man-toman conversations made toka sound natural and become well-known, and exactly the opposite may have happened to noka forms.

Apart from the reasons mentioned up to now, Legorburu (2018) also talks about the transmission gap. Similarly, Echeverria (2003) discusses school textbooks in which hika usage is constrained by gender and most exemplars use male rather than female forms. What is more, the few cases where noka is used in these textbooks tend to involve mythological figures with negative connotations that are not respected symbols of femininity who engage in hika conversations.

\subsection{Research questions}

In this theoretical part of the research, we have placed the study of hika usage in a broad context. We have explained the situation of the Basque language and the hika form of address, we have talked about gender differences in the use of languages, and we have presented some hypotheses about the reasons for the decline of these forms. These theoretical ideas lead us to formulate two intertwined research questions:

1. Does declared survey data confirm the decreasing trend of female hika forms?

2. Which are the reasons for the decline of female hika forms according to the participants?

In the following sections, we will see on the one hand how large differences in hika usage exist in the use among men and women, and that some of the reasons behind this phenomenon are consistent with those proposed by extant theorists.

\section{Materials and methods}

This study takes place in a town called Azpeitia, which is located in the heart of Gipuzkoa, the most Basque-speaking province of the Basque Country. Azpeitia has a population of nearly 15,000 and is one of the few towns with more than 10,000 inhabitants where the position of Basque is very strong. According to the last measurement of the street use of languages, $81.9 \%$ of the participants were using Basque (Soziolinguistika Klusterra, 2016). Not only is Azpeitia a stronghold of the Basque language itself, but it is also one of the places where the informal form of address hika is naturally used on a daily basis (Soziolinguistika Klusterra, 2016).

The source of our data is an online questionnaire with open and closed questions intended to get both numeric and narrative answers. We designed a comprehensive questionnaire that includes items related to personal data, language competence, and language practices, as well as participants' opinions towards some issues regarding hika. As shown in Table 2, we divided the participants into two age groups: adults (over 18 years old) and secondary education students (12-18 years old). Adults' numeric data were then disaggregated into five age groups to allow us more accurate analyses. 
Table 2. Description of participants

\begin{tabular}{|c|c|c|c|}
\hline \multirow{3}{*}{$\begin{array}{l}\text { Secondary education } \\
\text { students }\end{array}$} & Age range & Number & Gender \\
\hline & $12-18$ & $n=397$ & Female: $52.3 \%$ \\
\hline & & & Male: $46.7 \%$ \\
\hline \multirow{10}{*}{ Adults } & $18-25$ & $\mathrm{n}=91$ & Female: $73.1 \%$ \\
\hline & & & Male: $26.9 \%$ \\
\hline & $26-35$ & $\mathrm{n}=170$ & Female: $70.6 \%$ \\
\hline & & & Male: $29.4 \%$ \\
\hline & $36-45$ & $\mathrm{n}=301$ & Female: $69.3 \%$ \\
\hline & & & Male: $30.7 \%$ \\
\hline & $46-60$ & $\mathrm{n}=207$ & Female: $63.5 \%$ \\
\hline & & & Male: $36.5 \%$ \\
\hline & +61 & $\mathrm{n}=81$ & Female: $50 \%$ \\
\hline & & & Male: $50 \%$ \\
\hline
\end{tabular}

The questionnaires were adapted for each age group. The adults had more items in the questionnaire. Some of these were open-ended questions, considering adults' capacity to reflect on more complex issues and to put complex ideas into words. The narrative answers that we will show here consider the possible reasons for the decline of noka, and they all have been collected from the adults' questionnaire.

The questionnaires were delivered differently to adults and to students. For the students, we passed the questionnaire during school hours. We selected half of the total number of secondary education students in Azpeitia and they all answered the questionnaire $(n=397)$. Slightly over half of the respondents were female.

The data from adults have different characteristics because they were collected using the virtual snowball sampling technique (Baltar \& Brunet, 2012). Specifically, the questionnaire was distributed via Facebook, Twitter, Whatsapp, and email. We also resorted to word-of-mouth communication to get as many participants as possible. We took copies of the printed version to the retirement home, as the elderly are a difficult group to access via social networks. We collected 850 responses from adults, two-thirds of these from women.

Quantitative and qualitative analyses of the data collected were performed. For the first research question we carried out different statistical analyses: we extracted frequencies of the use of hika, tested differences by gender (male vs. female) and age (six age intervals ranging from 12 to 87 years old), and then we created contingency tables, chi-square, and Phi coefficient as a measure of effect size in categorical variables. An alpha value of 0.05 was considered significant. Qualitative data were triangulated with a second researcher in order to increase the credibility and validity of the results and reduce the risk of bias. We used SPSS version 24.0 for the numeric data and NVivo version 11 for the narrative data. 


\section{Results}

\subsection{Does declared survey data confirm the decreasing trend of female hika forms?}

According to Alberdi (1993), there are primarily two contexts where an hika conversation is likely to take place: friendly relationships and sibling relationships. We took into account these two contexts in our survey, and consider relevant results in the following paragraphs.

In Figure 1 we see the form of address participants generally use in friend-to-friend relationships, depending on the gender of the speaker and the hearer:

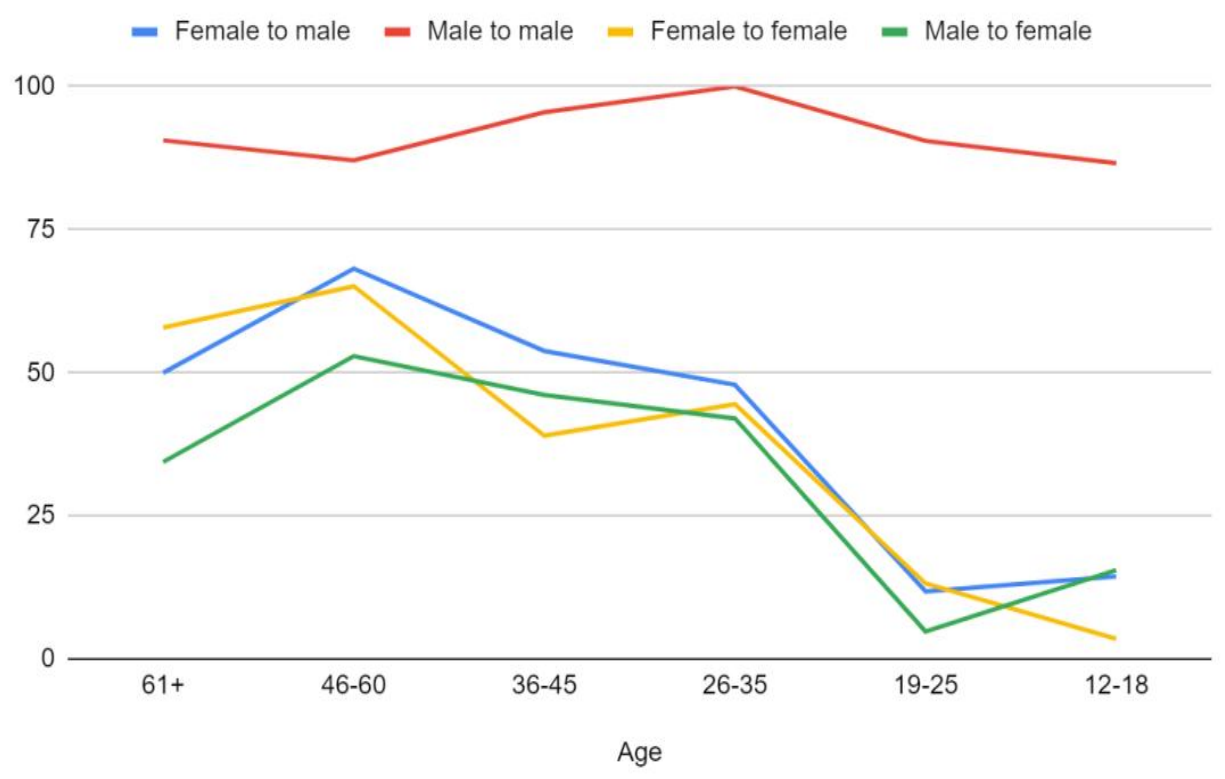

Figure 1. Use of hika among friends (\%).

The data that is presented in the graph refers to the percentage of people who use hika. Data from adult and young participants were collected by using a different questionnaire for each group, but the items used in this graph were the same in both questionnaires. The higher line accounts for male-tomale conversations and no matter the age group, the percentage of participants that use hika in this communicative context is around $90 \%$.

However, the decreasing trend is very clear in the rest of the cases, that is, men talking to women, women talking to men, and women talking to women. All these represent a similar tendency with slightly different fluctuations. For instance, it is meaningful that women over 45 seem to use hika with both women and men, with percentages ranging from $46.5 \%$ up to $69.2 \%$. Likewise, the presence of hika whenever a man is not involved in the conversation decreases dramatically in the 18-25 age group, and virtually no women under the age of 18 are addressed in hika either by men or women nor do they generally use it to address men.

As shown in Table 3, the results tell us that when the addressee is male, gender differences between speakers are statistically significant in all age cohorts, especially among the youngest age cohorts (1218 and 19-25), who had moderate or high effect sizes. In the case of female addressees, it is only among adolescents that the gender factor is statistically significant concerning the use of hika, although they are weakly associated according to Phi-values. Besides, it is one of the few age groups (together with 36-45) in which more men than women seem to use hika with female friends. 
Table 3. Use of hika among friends

\begin{tabular}{|c|c|c|c|c|c|c|c|c|c|}
\hline \multirow{2}{*}{$\begin{array}{l}\text { Age } \\
\text { group }\end{array}$} & \multirow[t]{2}{*}{ Gender } & \multirow[t]{2}{*}{$\mathrm{n}$} & \multicolumn{3}{|c|}{ Female friends } & \multicolumn{4}{|c|}{ Male friends } \\
\hline & & & $\%$ & Chi & $\mathrm{Phi}$ & $\mathrm{n}$ & $\%$ & Chi & Phi \\
\hline & q & 9 & 3.5 & & & 32 & 12.4 & & \\
\hline \multirow[t]{2}{*}{$12-18$} & $0^{\pi}$ & 36 & 155 & .000 & 0.212 & 201 & 86.6 & .000 & 0.740 \\
\hline & q & 9 & 132 & & & 8 & 11.8 & & \\
\hline \multirow[t]{2}{*}{$19-25$} & $0^{\pi}$ & 1 & 48 & .282 & & 19 & 90.5 & .000 & 0.727 \\
\hline & ㅇ & 53 & 44.5 & & & 57 & 47.9 & & \\
\hline \multirow[t]{2}{*}{$26-35$} & $\hat{0}$ & 21 & 42 & .761 & & 50 & 100 & .000 & 0.493 \\
\hline & q & 82 & 39 & & & 113 & 53.8 & & \\
\hline \multirow[t]{2}{*}{$36-45$} & $0^{\lambda}$ & 41 & 46.1 & .259 & & 85 & 95.5 & .000 & 0.403 \\
\hline & q & 84 & 65.1 & & & 88 & 68.2 & & \\
\hline \multirow[t]{2}{*}{$46-60$} & $0^{\lambda}$ & 37 & 52.9 & .091 & & 61 & 87.1 & .003 & 0.208 \\
\hline & q & 22 & 57.9 & & & 19 & 50 & & \\
\hline $61+$ & $\sigma^{\lambda}$ & 11 & 34.4 & .050 & & 29 & 90.6 & .000 & 0.436 \\
\hline
\end{tabular}

Siblings have also traditionally tended to address each other in hika, although it has also been common for women to address their brothers using $h i$ and for men to answer using $z u$. As we can see in Figure 2, the use of hika again varies depending on gender as well as on age.

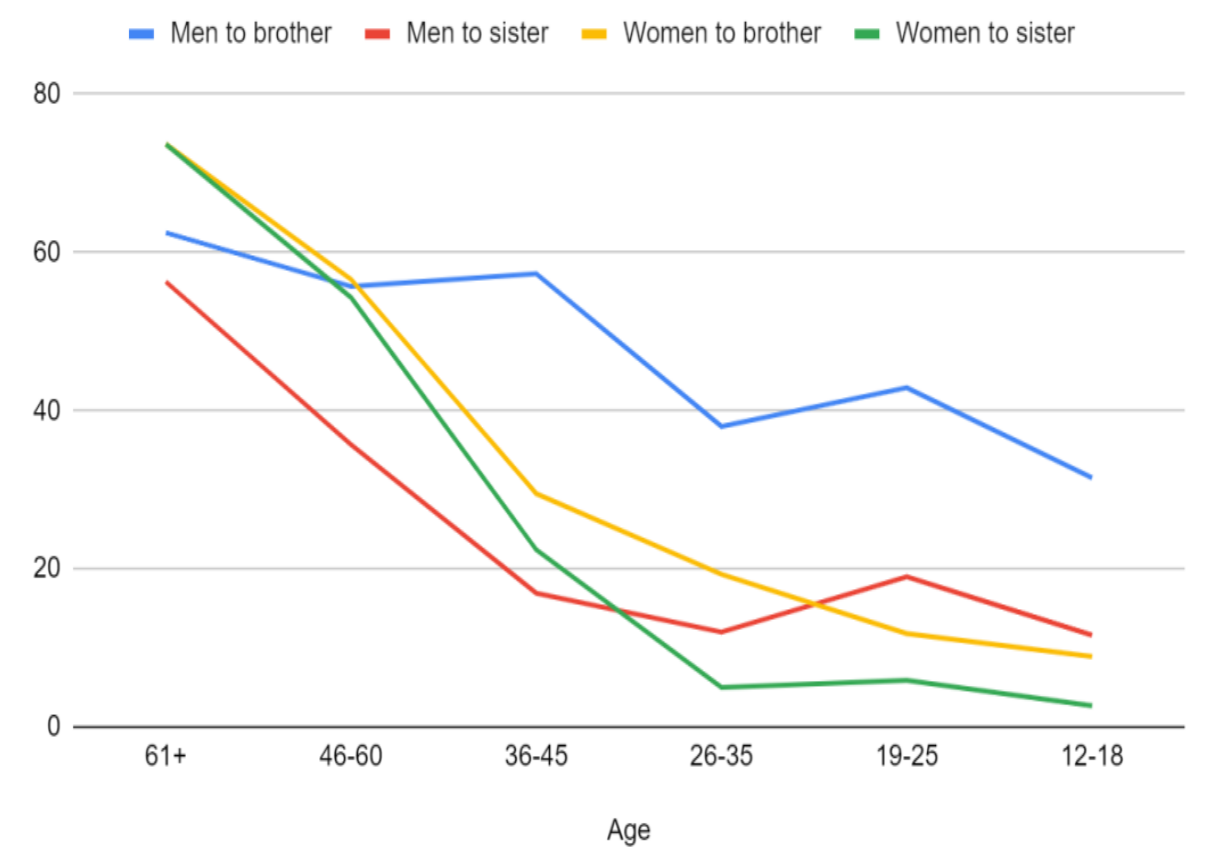

Figure 2. Use of hika among siblings (\%)

Among those participants who are 61 or older, about $80 \%$ of them use the informal form of address, both women and men addressing their sister or their brother almost equally. If we consider all age groups, we realize that the highest use takes place between brothers, but there is a downward 
tendency here, too, as we look at younger generations. The use is as high as $75 \%$ among those over 61 , whereas half of the male adolescents aged 12-18 use hika with their brothers. The use of hika drops drastically among younger participants when there is a female agent in the communicative act. The percentages are especially low among women under 35 addressing other women, where using hika is negligible.

The statistical analyses of the data about sibling communication show more inconsistencies. We can see the data in Table 4:

Table 4. Use of hika among siblings

\begin{tabular}{|c|c|c|c|c|c|c|c|c|c|}
\hline \multirow{2}{*}{$\begin{array}{l}\text { Age } \\
\text { group }\end{array}$} & \multirow[t]{2}{*}{ Gender } & \multicolumn{4}{|c|}{ To sisters } & \multicolumn{4}{|c|}{ To brothers } \\
\hline & & $\mathrm{n}$ & $\%$ & Chi & Phi & $\mathrm{n}$ & $\%$ & Chi & Phi \\
\hline & q & 7 & 2.7 & .000 & 0.184 & 23 & 8.9 & .000 & 0.290 \\
\hline \multirow[t]{2}{*}{$12-18$} & $\hat{0}$ & 27 & 11.6 & & & 73 & 31.5 & & \\
\hline & q & 4 & 5.9 & .065 & & 8 & 11.8 & .002 & 0.336 \\
\hline \multirow[t]{2}{*}{$19-25$} & $\hat{\sigma}$ & 4 & 19 & & & 9 & 429 & & \\
\hline & q & 6 & 5 & .108 & & 23 & 19.3 & .010 & 0.197 \\
\hline \multirow[t]{2}{*}{$26-35$} & $\hat{\sigma}$ & 6 & 12 & & & 19 & 38 & & \\
\hline & q & 47 & 22.4 & .281 & & 62 & 29.5 & .000 & 0.262 \\
\hline \multirow[t]{2}{*}{$36-45$} & $\hat{0}$ & 15 & 16.9 & & & 51 & 57.3 & & \\
\hline & q & 70 & 54.3 & .012 & -0.177 & 73 & 56.6 & .905 & \\
\hline \multirow[t]{2}{*}{$46-60$} & $\hat{0}$ & 25 & 35.7 & & & 39 & 55.7 & & \\
\hline & q & 28 & 73.7 & .126 & & 28 & 73.7 & .315 & \\
\hline $61+$ & $\hat{0}$ & 18 & 56.3 & & & 20 & 62.5 & & \\
\hline
\end{tabular}

The gender factor is statistically significant when addressing a sister only in two age groups (12-18 and 46-60), and the association is very weak in both. As for the form of address used towards brothers, the gender variable proves statistically significant only among those under 45 years old, and the correlation is at best low.

The two datasets we have seen give us a rough picture of the difference in the use of hika among participants belonging to different age groups. Whereas the eldest cohort (61+) seems to respond to the traditional use of hika in these given contexts, as age lowers, the gender category becomes crucial, especially among those younger than 45 years old. In the adolescent group (age=12-18) it is only among male friends that the use of hika remains strong, and it enjoys good health among brothers, too. However, when a woman has involved the use of hika decreases, be it among friends or siblings, especially when both the speaker and the hearer are female.

\subsection{Which are the reasons for the decline of female hika forms according to the participants?}

In our questionnaire, we asked our adult participants to select among different options to explain the alleged decline of female hika forms. They could choose more than one option and that is why the total sum of tokens $(\mathrm{N}=886)$ is higher than the number of participants. We carried out statistical analyses to see whether gender differences turned out significant but they were not or at most they had a very small associated effect size, that is why we did not include them here. Over half of the 
participants $(51.8 \%)$ answered that they do not know why the use of the form has declined. Regarding the other options given, about $13.2 \%$ of the participants pointed to the bad prestige of female forms of hika; that is, the notion that women speaking hika are considered rude is seen as the most influential factor. Others responded that the fact that hika forms to address women are impolite for many people has caused its decline $(4.1 \%)$ and others indicated that female hika forms might be seen as unnecessary $(2.5 \%)$. About one-third of the participants $(\mathrm{n}=286)$ chose the option "Other reasons", which they were asked to specify in an open-question item. We classified all the ideas into eight different categories. As we can see in Figure 3, most participants suggested reasons related to lack of habit, lack of knowledge, the transmission gap, and bad prestige. A considerable number also mentioned sexism explicitly.

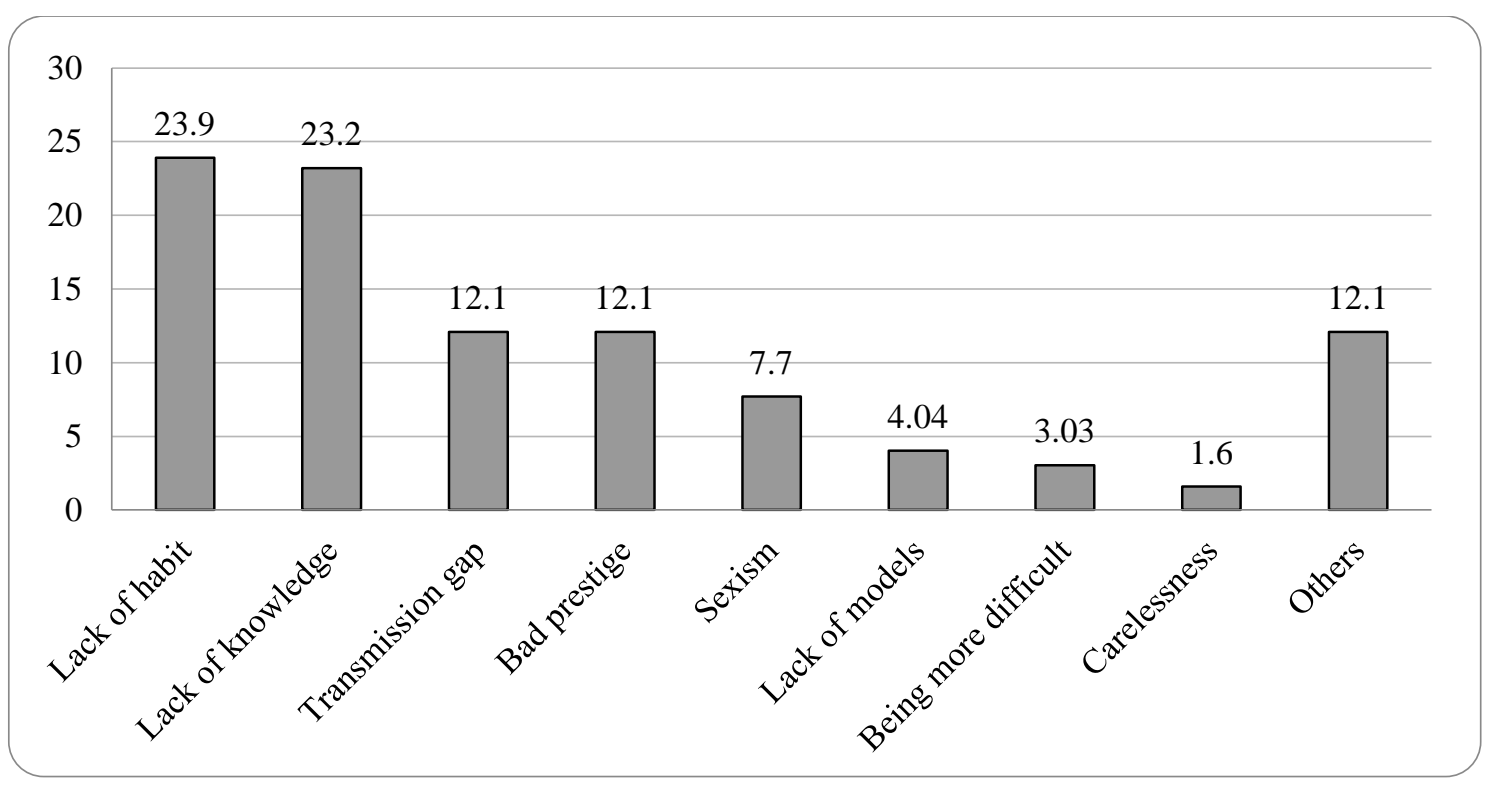

Figure 3. Reasons for the decline of noka forms

Once we have seen the figures of the different categories, we will go through a sample of the actual comments we received. All of them were written in Basque (either standard or local dialect) but we will only show the English translation of some of the most representative comments grouped accordingly. Among those who wrote an answer different from the options we provided, most of them thought that lack of habit is a key factor for the loss of noka forms. Here is a comment that illustrates this point of view:

"Lack of habit (unfortunately even though we long for equality I'm the one who uses hika with a handful of women and then we [men] address all men like that). Not because it's better or worse. [AZ-301]

Together with lack of habit, the general low command of female hika forms has been argued as one of the main reasons for their loss:

We don't know how to speak in noka. [AZ-822]

Some of the answers combine the previous two opinions:

I think using hika has always been more common among men, that's why I think using noka [so little] is a consequence of that, the fact that people don't know how to use it properly. [AZ-634]

Related to lack of habit, some of the participants have mentioned the resulting challenge of using noka forms:

We find it more difficult because we're not used to speaking it because we don't use it (in general). [AZ775] 
We have also collected comments that go beyond lack of habit and knowledge. That is, some participants have mentioned what the actual reasons might be behind those factors: the transmission gap and lack of models from whom they could have learned how to use noka properly. Here is a comment that illustrates those two ideas:

The transmission has been poorer, at home our parents taught us less [than toka] how to speak in noka. We haven't been taught at school either. [AZ-462]

Rather than pointing at previous generations, a few make those who do not use them responsible for the loss of female forms, referring to carelessness:

It is not valued and many people don't care about using it right or wrong. [AZ-665]

In the questionnaire that the participants completed, among the options, we suggested as putative reasons for the loss of noka, "lack of prestige" was one of them and 13.6\% of the participants chose that option. However, 36 more participants wrote about that very same issue in the open question. Some participants mentioned that using noka has been related to lack of respect, like in the following example:

I think it can be due to a lack of respect, not because it actually is disrespectful [using noka], but because we have been taught so. [AZ-516]

In the same vein, some have perceived a link between speaking noka and bad manners. That opinion is illustrated in this comment:

I think that comes from a long time ago, as if it was a sign of bad education in the past, especially among women (unfortunately). [AZ-230]

Some others think that using the female form of hika has been deemed as rude or coarse:

When we were young, we were told that women using noka was impolite. [AZ-464]

In some segments [of society], some have considered it crude or disrespectful. [AZ-809]

A certain number of participants have admitted that noka provokes negative reactions on them:

It sounds harsh to me, uncouth, rude. [AZ-22]

Together with the bad press that female hika forms have had and still may have, the undesired feminine touch of noka has been mentioned as another factor that may have influenced the decrease of the use of noka among men:

Some of those [men] who always use toka may think that speaking in noka is a feminine feature... I mean, they reassert their manliness. Prejudices...! [AZ-738]

As we said before, sexism is another recurrent factor that was suggested by the participants. These are some of the most representative comments concerning this issue:

Gender roles are imposed since we are children and the use of hika is another sign. Considering it is a communication channel of certainty, confidence, and comfort, fears that are assigned to women, 'the need of not doing it wrong'... determine its use. [AZ-309]

Because we are quite sexist because we think we have to treat women with tenderness. [AZ-311]

In this section of the results, we have seen that large differences exist in the use of hika between men and women, so much so that female forms are not far from becoming extinct. We have also tried to explain public perceptions of the main reasons for this development. The online questionnaire format might not have facilitated a deep and elaborate reflection of such a multifarious issue, but responses generally point in the same direction. These ideas will be contrasted and discussed in the next section. 


\section{Discussion}

\subsection{Does declared survey data confirm the decreasing trend of female hika forms?}

Previous research on the use of hika has shown that the use of noka has decreased considerably, and also that women are addressed in that way less and less by men (Azkue, 2000; Echeverria, 2003). Our data, based on a declared survey and focused on a town where the informal form of address is still strong, show that the younger the female participants, the lesser they use hika and are addressed so, providing compelling support for a decreasing tendency. We can state that differences are indeed remarkable between men and women, in line with the results that Alberdi (1993) obtained in his research.

In order to interpret those data rigorously, there is a phenomenon that needs to be taken into consideration, namely what has been labeled in Catalan 'linguistic muda.' This concept refers to the idea that bilingual speakers may change their language uses in different contexts and socially defined life stages. Pujolar and Puigdevall (2015) identified six main biographical moments in which these mudes took place: (a) when entering primary school; (b) when entering high school; (c) when entering the university; (d) when entering the labor market; (e) when creating a new family; and (f) when becoming a parent.

In the case of our research, it is not a different language that integrates into the language repertoire of the speakers, but a different variety within the same language, namely another form of address. Nonetheless, we see developments similar to the linguistic muda phenomenon to the extent that speakers have added a new way of communicating in their language repertoire which could influence the construction of a new linguistic persona. According to what we see in our data, young participants, especially women, seldom use hika. In the reasoning of Pujolar and Puigdevall (2015), these female adolescents have not done the linguistic muda. We would need a longitudinal study to check whether those girls at some point add hika to their language repertoire and this phenomenon might be analogous to the so-called linguistic muda.

For now, in the particular case of Azpeitia, hika could be labeled as the default form of address among men, but the rest of the gender combinations may be at crossroads and their future is not easy to predict. In any case, our results are in agreement with the few studies carried out so far to measure the use of hika (Soziolinguistika Klusterra, 2016).

Alberdi (2018) explained that same-sex conversations facilitate the use of hika, but we saw that this criterion mostly applies to man-to-man relationships and does not take place among women. In fact, it is more commonly used in mixed than in woman-to-woman conversations.

However, related to that trend, another idea worth mentioning is the appropriate-and inappropriate-use of hika. In the theoretical section, we explained that not long ago women sometimes started to be addressed using male forms of hika both by men and by other women (Azkue, 2000; Barquín, 2008; Ozaita, 2015). Our research does not offer evidence to either support or refute this phenomenon as it was not included in the questionnaire. That is, we cannot say whether those who state that they use hika do it correctly or incorrectly. In the studies included in the theoretical framework, we have mentioned the incorrect use is present, and we suspect the same trend is likely to be reproduced among our participants. This is an area of additional work that we are now pursuing.

The criteria presented by Alberdi (1993) were essential to understand the nature of the use of the Basque informal address form. Yet, the sociolinguistic aspect of hika has undergone a considerable change in the last decades, and what Alberdi explains can only be applied to the senior generations, as younger speakers do not obey those social rules very strictly. For example, we have seen that the closer the relative, the more common it will be to speak in hika (Alberdi, 1993). In our data most 
siblings do not use hika among themselves, with a major exception: the eldest group, who still seems to respect the traditional use and typically address their brothers and sisters in hika, no matter the sex of the speaker and the hearer. In contrast to what Alberdi (1993) observed, we did not see that women address their brothers in hika easier than vice versa in all age groups. Specifically, the participants under 26 performed in the opposite direction. Again, we should look at possible inadequate use of the male forms when addressing women, which seems to be more widespread among young speakers.

In sum, to answer the first research question, we are witnessing an overall decline of hika in Azpeitia, one of the strongholds of the informal form of address. This decline can be observed by just taking a glance at the use of hika by different generations in the graphs, as elderly people use it more than younger adults and teenagers in the contexts we have shown here. However, gender turns out to be a crucial factor: as we look at younger age groups, the gender gap continually increases, and among teenagers, hika is almost exclusively used in man-to-man conversations. This ever-decreasing trend of hika whenever a woman is involved clearly indicates that a decline is actually taking place, and the youngest hardly preserve this feature of the Basque language.

\subsection{Which are the reasons for the decline of female hika forms according to the participants?}

Considering possible reasons behind the decrease of female forms of hika, both previous studies (e.g., Legorburu, 2018) and our own mention the transmission gap as a possible influential factor. However, the notion of a transmission gap still fails to provide an explanatory mechanism for the phenomenon. In other words, not transmitting a language - or a given aspect of a language, in the present case- - happens due to different factors, and even though respondents mentioned this idea as a factor, we should go beyond and seek the actual reasons behind the lack of transmission.

One compelling explanatory for the decline of the female hika form involves the ideas of Labov (1972) and Echeverria (2003): the low prestige of this form. To fully understand this idea, we need to delve into why female forms at some point acquired such a stigma. That would lead us to ideas developed from a poststructuralist feminist approach (Piller \& Pavlenko, 2004) as well as some of the results presented in this study. Ochs (1992) claims that in the context of a given community of practice, language is one of the resources used as an identity marker. In the same vein, Echeverria (2003) talks about the "iconic relationship between $h i$ and masculinity" (p. 405). Some factors associated with that concept appear in the participants' answers linked with sexism. This is important in linking the social structures of masculinity with the use of a specific form of address.

Some participants mentioned sexism explicitly, but the effect of sexism is also present behind other factors that participants referred to, such as lack of habit, low command of female hika forms, lack of models, or the undesired feminine touch of noka. As we will discuss in the section concerning the general conclusions, these results stem from the insights of not actual experts but ordinary people involved in this process of decrease. This approach may open up new perspectives for research in the future.

\section{Conclusions}

We started working on a simple issue in this study, but once we dug into the decrease of noka forms, we came up with a multifarious phenomenon that is worth investigating. It does not simply indicate the fade-out of a given aspect of a language, but it also tells us about how women have been expected to talk, a possible change of paradigm in this respect, and also how working patterns can affect language use and how that impact can be unequal depending on different factors such as gender. All these make a specific issue interesting from a universal point of view. 
Thus, our results show the situation of the female structure of the informal form of address that is only spoken by a proportionally small group among the speakers of a European minority language with roughly one million speakers. However, even if the potential population affected by our research topic is quantitatively limited, this phenomenon certainly has implications for other contexts. The present study deals with a particular linguistic feature, but it cannot be regarded as an isolate since gender differences have been observed to make an impact in language use.

Several factors are included here that can explain -at least to a certain degree- a complex trend, but it would be indispensable to go deeper into it to fully understand the underlying reasons behind the pronounced decrease of the female forms of hika, or more precisely, the use of hika among women.

Related to that, we realize that we posed a truly complicated question to the people of the Basque town of Azpeitia and that not anybody may feel capable of answering. Not in vein, the majority of participants reported not knowing the actual reasons for the decline of female forms of hika, even when they had other options to choose from. The appropriateness of regular people to look into such a deep issue may be put into question, but this is a phenomenon that is taking place right now, and we consider it important to collect the testimonies and personal experiences of the people involved in this ongoing evolution of language use. From an epistemological perspective, other research tools and more qualified participants may shed more light on this issue in the future.

We are also concerned about the fact of extrapolating the results from a single town to the rest of the Basque-speaking territory. However, folk wisdom has it that this trend is a general one, and other studies carried out in other areas show similar patterns to those we present here. Then, we should be cautious and we should not draw far-reaching conclusions from our results in this respect, but we are afraid we would not find many areas where the female form of hika is in a much better position. Our approach reduces the scope of the study, but at the same time strengthens the validity of the results.

In our study, we have observed a decreasing trend of female forms of hika as well as large differences between women and men. We argue that the reasons behind this tendency are a consequence of structural gender differences in society. However, certain small communities are raising awareness of this reality and some have started to consider the female forms as a tool for empowering women. Therefore, only time will tell whether the current meanings of both feminine and masculine forms of hika will remain as such or they will turn into something different in the years to come.

\section{Ethics Committee Approval}

The authors confirm that this study does not need ethics committee approval.

\section{References}

Alberdi, X. (1993). Hika tratamenduaren balore sozio-afektiboak. Fontes Linguae Vasconum, 64, 425442. http://www.culturanavarra.es/uploads/files/05_FLV64-0425-0442.pdf

Alberdi, X. (2018). Forms of address in Basque. Pragmatics, 283, 303-332. https://doi.org/10.1075/prag.00009.alb

Azkue, X. (2000). Hitanoa Zumaian. Zumaia: Zumaiako Udala.

Baltar, F., \& Brunet, I. (2012). Social research 2.0: virtual snowball sampling method using Facebook. Internet Research, 22(1), 57-74. https://doi.org/10.1108/10662241211199960 
Barquín, A. (2008). Euskararen Erabilera ez Sexista. Vitoria-Gasteiz: ZURE Estudios gráficos. https://www.euskadi.eus/eusko-jaurlaritza/-/liburua/euskararen-erabilera-ez-sexista/

Beitia, I. (2017). Tokanoka tribua. Eskoriatzako gazteak eta hitanoa: uste, balore eta jarrerak. BAT $\begin{array}{lll}\text { Soziolinguistika Aldizkaria, 139-166. } & \text { 103, }\end{array}$ http://www.soziolinguistika.eus/files/inigo_beitia_bat103.pdf

Chambers, J. K. (1995). Sociolinguistic Theory. Oxford: Blackwell.

de Rijk, R. P. G. (1991). Familiarity or solidarity: The pronoun hi in Basque. Revista Internacional de los Estudios Vascos, 36(2), 373-378.

Echeverria, B. (2003). Language ideologies and practices in (en)gendering the Basque nation. Language in Society, 32(3), 383-413.

Echeverria, B. (2016). Harlots and whores but not lovers. Dressing down the pronoun for a female addressee in a Basque Old Testament. In J. A. \& F. H. Baider (Eds.) Gender, Language and the Periphery (pp. 353-80). Amsterdam/Philadelphia: John Benjamins.

Gal, S. (1979). Language Shift: Social Determinants of Linguistic Change in Bilingual Austria. New York: Academic Press.

Holmes, J. (2007). Social constructionism, postmodernism, and feminist sociolinguistics. Gender and Language, 1(1), 51-65. doi: 10.1558/genl.2007.1.1.51

Juanena, A. (1991). Hizkuntz sexismoa eta euskara. Jakin, 65, 97-110. https://www.jakin.eus/show/e811915964a32de3618523331f87587407df0498

Labov, W. (1972). Sociolinguistic Patterns. Philadelphia: University of Pennsylvania Press.

Lakoff, R. (1973). Language and woman's place. Language in Society, 2(1), 45-80.

Lakoff, R. (1975). Language and Woman's Place. New York: Harper \& Row.

Legorburu, O. (2018). Genero rolek hitanoaren erabileran izan duten eragina: Antzuolako herritarren diskurtso eta praktikak. BAT Soziolinguistika Aldizkaria, 109(4), 111-138. http://www.soziolinguistika.eus/files/onintza_legorburu_larrea_109.pdf

Litosseliti, L., Gill, R., \& Garcia Favaro, L. (2019). Postfeminism is a critical tool for gender and language study. Gender and Language, 13(1), 1-22. doi: 10.1558/genl.34599

MacDonald, M. (1989). We Are not French: Language, Culture, and Identity in Brittany. New York: Routledge.

Ochs, E. (1992). Indexing gender. In A. Duranti \& C. Goodwin. (Eds.) Rethinking Context (pp. 335358). Cambridge: Cambridge University Press.

Oyharçabal, B. (1993). Verb agreement with nonarguments: On allocutive agreement. In J. I. Hualde \& J. Ortiz de Urbina. (Eds.) Generative Studies in Basque Linguistics (pp. 89-114). AmsterdamPhiladelphia: John Benjamins.

Ozaita, J. (2014). Tolosaldeko gazteek (16-28) hitanoari buruz duten pertzepzio, diskurtso eta praktika. $\begin{array}{llll}\text { BAT Soziolinguistika } & \text { Aldizkaria, }\end{array}$ http://www.soziolinguistika.eus/files/Josu\%20Ozaita.pdf

Piller, I., \& Pavlenko, A. (2004). Bilingualism and gender. In T. K. Bhatia \& W. C. Ritchie (Eds.) Handbook of Bilingualism (pp. 489-511). Oxford: Blackwell. 
Pujolar, J., \& Puigdevall, M. (2015). Linguistic mudes: how to become a new speaker in Catalonia. International Journal of the Sociology of Language, 231, 167-87. doi: 10.1515/ijsl-2014-0037

Soziolinguistika Klusterra (2016). Azpeitiko hizkuntza-erabileraren eta hitanoaren presentziaren kaleneurketa. Emaitzen txostena. [Measurement of the street use of languages and the presence of hika in Azpeitia. Report of results]. Andoain: Soziolinguistika Klusterra.

Trudgill, P. (1995). Sociolinguistics: An Introduction to Language and Society. London: Penguin.

Urla, J. (1995). Outlaw language: creating alternative public spheres in Basque free radio. Pragmatics, 5(2), 245-61. https://doi.org/10.1075/prag.5.2.09url

Urla, J. (2012). Reclaiming Basque: Language, Nation, and Cultural Activism. Reno, NV: University of Nevada Press.

West, C., \& Zimmerman, D. H. (1983). Small insults: A study of interruptions in cross-sex conversations between unacquainted persons. In B. Thorne (Ed.) Language, Gender and Society (pp. 102-17). Rowley, MA: Newbury House.

\section{AUTHOR BIODATA}

Garbiñe Bereziartua is a lecturer at the Department of Didactics of Language and Literature in the University of the Basque Country (UPV/EHU). She has analysed in depth the use of formal and informal language among young Basque speakers, and she is currently focused on the use of the Basque informal address form and its use among speakers.

Beñat Muguruza is a lecturer at the Department of Basque Language and Communication in the University of Basque Country (UPV/EHU). His PhD thesis focused on the use of English in UPV/EHU as a third language, and now he is also doing research on Basque sociolinguistics. 